\title{
Orthodromic sensory action potentials from palmar stimulation in the diagnosis of carpal tunnel syndrome
}

\author{
KR MILLS \\ From the Department of Clinical Neurophysiology, The National Hospital for Nervous Diseases, Queen \\ Square, London, $U K$
}

SUMMARY It is known that the major slowing of nerve conduction in the carpal tunnel syndrome occurs in the palm to wrist segment. A technique exploiting this fact and easily applicable in the routine laboratory would be useful in diagnosing early examples of the condition. To this end, orthodromic sensory potentials from stimulation of digits II and V, and of the palmar branches of the median and ulnar nerves were recorded at the wrist in 53 healthy hands, 72 hands with a tentative diagnosis of carpal tunnel syndrome and in 20 hands of patients with unrelated neurological conditions. Using conventional criteria, $53 \%$ of the 72 hands from those suspected of carpal tunnel syndrome were thought to have median nerve compression. When conduction velocity in median palm wrist fibres was taken into account, $67 \%$ of hands were then considered abnormal. It is concluded that orthodromic sensory action potentials from palmar stimulation provide a rapid, sensitive and acceptable method of diagnosing the carpal tunnel syndrome.

Compression of the median nerve at the wrist is the commonest entrapment neuropathy. It is now recognised that the condition can present with nontypical symptoms, especially early cases, and it is the impression that the number of such mild cases referred for diagnosis is increasing.

Several electrophysiological techniques are available to facilitate the diagnosis and are reviewed by Kimura. ${ }^{1}$ The simplest is measurement of the distal latency from supramaximal median nerve stimulation at the wrist to the onset of the response recorded by a needle in the abductor pollicis brevis muscle. It is now recognised that up to $30 \%$ of patients are undiagnosed by this technique. ${ }^{23}$ Sensory action potentials (SAPs) either generated orthodromically by stimulation of the digital nerves, ${ }^{4}$ or antidromically by following the reverse procedure $^{5}$ provide a greater number of positive diagnoses. Whilst the near-nerve needle recording technique exploited by Buchthal $e a^{3{ }^{36}}$ produces an even greater yield, it is invasive, and a large number of responses need to be averaged. However, their studies have shown that in the carpal tunnel syn-

Address for reprint requests: Dr KR Mills, The National Hospital for Nervous Diseases, Queen Square, London WC1N 3BG, UK.

Received 22 May 1984 and in revised form 19 July 1984. Accepted 21 July 1984 drome, the segment of nerve from palm to wrist shows the lowest velocity and that this may be the only detectable abnormality. These findings have been confirmed by Kimura ${ }^{78}$ using multiple stimulation sites across the wrist and recording antidromia responses in the digits, and by Eklund ${ }^{9}$ and Daube ${ }^{10}$ using orthodromic techniques. Since median nerve entrapment is commonly bilateral, abnormalities in nerve conduction cannot be inferred from a comparison of the two sides; provided that a concurrent ulnar nerve lesion is excluded, comparison of median and ulnar SAPs then provides a useful control, and may improve diagnostic yield. ${ }^{11}$ This tactic also avoids errors due to differences in hand temperature between subjects.

The results of large series of patients who have undergone surgical decompression indicate that early surgery is advisable ${ }^{12-14}$ and thus techniques to diagnose the condition at an early stage should continue to be sought. The tests should, however, be robust and rapid in execution in order to be applicable in a busy laboratory, but should not be so sensitive that false positive diagnoses are made.

This paper reports a systematic study of orthodromic sensory action potentials recorded at the wrist with surface electrodes from stimulation of the digits (II and V) and from stimulation of the palmar branches of the median and ulnar nerves. Data were collected from a control group, an unselected series 
Table 1 Summary of clinical features in patients with possible median nerve compression

\begin{tabular}{ll}
\hline & Number \\
\hline Total patients & 47 \\
Total hands & 72 \\
Males (age 38-71 yr) & 11 \\
Females (age 29-74 yr) & 36 \\
Patients with bilateral symptoms or signs & 25 \\
Patients with unilateral symptoms or signs & 22 \\
Hands with sensory symptoms & 64 \\
Hands with nocturnal pain & 34 \\
Hands with motor symptoms & 16 \\
Hands with sensory signs & 19 \\
Hands with motor signs & 17 \\
Hands having had previous surgery & 13 \\
Length of history 0-3 months & 20 \\
Length of history 3-12 months & 17 \\
Length of history 1-5 years & 29 \\
Length of history more than 5 years & 6 \\
\hline
\end{tabular}

of patients with symptoms and/or signs possibly due to the carpal tunnel syndrome, and a series of patients with unrelated neurological diseases.

\section{Patients and subjects}

\section{Groups of subjects}

Group 1: Hospital staff with no known history or signs of neurological disease formed the control group. There were 16 males (age range 19-63 yr) and 13 females (age range $19-61 \mathrm{yr}$ ) and a total of 54 median and ulnar nerves were examined. One male control was excluded because conventional tests indicated a carpal tunnel syndrome.

Group 2: Patients referred with the tentative diagnosis of carpal tunnel syndrome were examined. No other selection procedure was used. In all, 72 hands from 47 patients were tested. The clinical details of these patients are summarised in table 1.

Group 3: A series of 20 patients (10 males, 10 females; age range 19-75 yr) also referred, with conditions unrelated to entrapment neuropathy for example primary muscle disease, hysteria, multiple sclerosis were also examined.

\section{Methods}

Sensory action potentials from digits (II and V) were recorded by the same technique described by Gilliatt and Sears 4 except that eight responses were electronically averaged. Saline soaked lint covered silver strips were wrapped around the base of the finger and the distal interphalangeal joint (fig 1). Recording electrodes of the saddle type ${ }^{15}$ with separation $3 \mathrm{~cm}$ were placed over the relevant nerve at the distal wrist skin crease and signals were amplified, bandpass filtered between $32 \mathrm{~Hz}$ and $3 \cdot 2 \mathrm{kHz}$ before averaging. Stimuli were $100 \mu$ s pulses at a voltage sufficient to give a maximal response and were repeated at $1 / \mathrm{s}$.

Sensory action potentials from palmar stimulation: The recording electrodes, amplifier, filters and averaging were identical to the digital SAP procedure. Stimulation of the palmar branches of the nerves was achieved by using a bipolar stimulator with inter-electrode distance of $1.5 \mathrm{~cm}$. The distal skin crease was marked and identical distances were measured with the hand flat, towards the webs be-

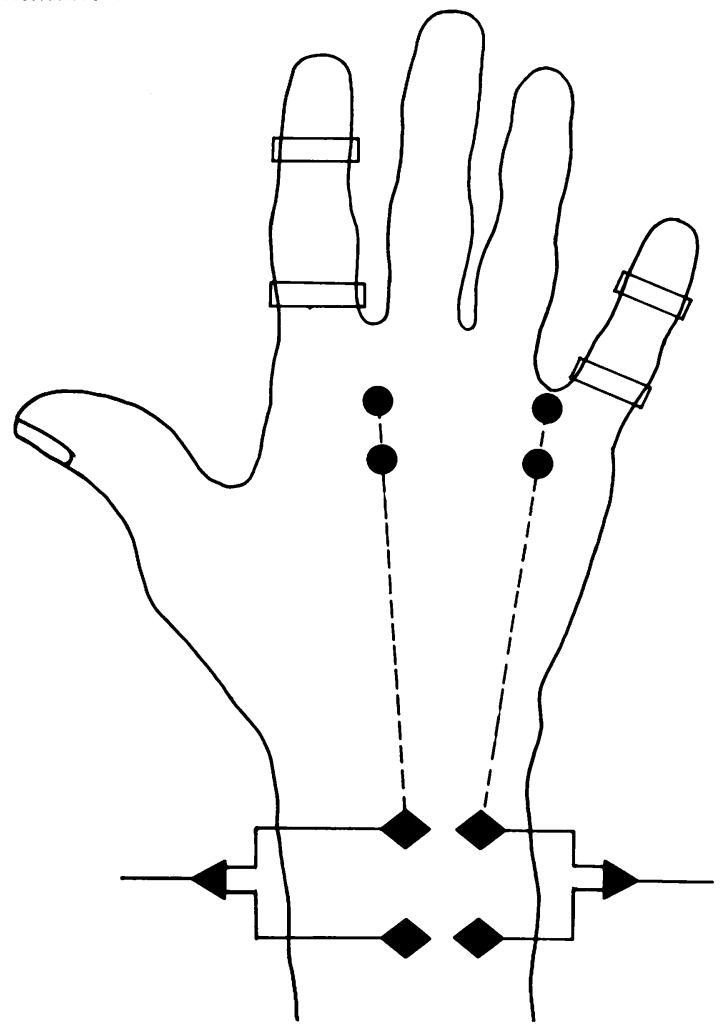

Fig 1 Recording positions at the distal skin crease over the median or ulnar nerves with saddle type electrodes (separation $3 \mathrm{~cm}$ ). Stimulation of the digits (II or V) using saline-soaked lint wrapped silver strips and of the palm using a bipolar stimulator (separation $1.5 \mathrm{~cm}$ ) at identical distances $(8.5-11 \mathrm{~cm})$ along the palm from the wrist recording sites.

tween the 4th and 5th digits and between the 2nd and 3rd digits; this gave the position of the cathode (fig 1).

Other electrophysiological tests: All patients with a possible carpal tunnel syndrome had the abductor pollicis brevis muscle examined by concentric needle electromyography and the distal motor latency to the muscle from supramaximal median nerve stimulation at the wrist measured. Other muscles were sampled and other nerve conduction studies performed if indicated.

Measurements. Peak to peak amplitude of SAPs was measured. Onset latency was measured as the time to the first negative deflection from the baseline, or as the time to the first positive peak (if present). Conduction velocity was calculated using the distance between stimulating cathode and active electrode.

Errors. No attempt was made to control temperature rigorously, but if the hands of patients or controls were obviously cold, they were warmed for $5 \mathrm{~min}$ in water. Distances were measured with a flexible tape and were to the nearest $0.5 \mathrm{~cm}$; latencies were measured to the nearest $0.05 \mathrm{~ms}$ (fig 2). In the range of distances used and laten- 
Normal

Carpal tunnel syndrome

Calibration: 10 microV
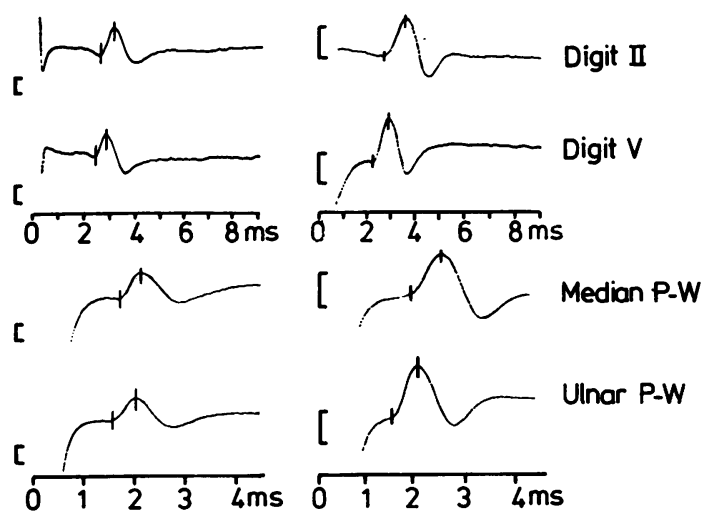

Fig 2 Examples of recordings obtained from a healthy subject and a patient with clinically mild carpal tunnel syndrome. The sensory potential from digit II in this patient fell within the normal range for peak latency, but conduction velocity in the palm-wrist segment was $43 \mathrm{~m} / \mathrm{s}$ for median fibres and $56 \mathrm{~m} / \mathrm{s}$ for ulnar fibres.

cies encountered, in the worst case this would give an error in conduction velocity of $3.8 \mathrm{~m} / \mathrm{s}$. It is possible that motor fibres innervating the lumbrical muscles may have been activated antidromically by palmar stimulation, but twitches of these muscles were never observed, and it seems likely that their contribution to the wrist response is small.

\section{Results}

In 23 of the healthy subjects, palmar velocities and digital SAP peak latencies from the two hands were compared ( $t$ test for non-independent samples) and no statistical difference was found between them ( $p$ $>0.5$ ) and so results were pooled. The results in normal hands are summarised in table 2 . In the palm to wrist segment, the conduction velocity in median fibres was $58.8 \mathrm{~m} / \mathrm{s}$ (SD 6.7); this compares with a previously reported value of $60 \mathrm{~m} / \mathrm{s}$ (SD 3.5$)^{3}$ using needle stimulation in the palm and needle recording at the wrist. The value in ulnar fibres in the same segment was $58.4 \mathrm{~m} / \mathrm{s}$ (SD 5.8). Palmar SAPs are greater in amplitude than the corresponding digital ones; this is to be expected because a greater number of sensory fibres are probably stimulated, and the shorter conduction distance leads to less dispersion of the potential.

Patients with possible median nerve compression In the 72 hands examined with possible median nerve compression at the wrist $24(33 \%)$ had a distal motor latency greater than $\mathbf{4 . 8} \mathrm{ms}$ (the upper limit of normal given by Thomas ${ }^{16}$ ). Clear signs of neurogenic change in the short thumb abductorfibrillations, a reduced number of motor units on maximal activation or polyphasic units of high amplitude firing at high rates, were found in only 10 (14\%) patients.

The criterion suggested by Gilliatt and Sears ${ }^{4}$ on digital SAPs for median nerve compression that is a peak latency greater than $4.0 \mathrm{~ms}$, was reached in 177 hands $(24 \%)$. The value of peak latency which was 2 . standard deviations above the mean for the healthy controls in this series was $3.3 \mathrm{~ms}$ and $38(53 \%)$ hands were then considered abnormal. The digit II peak latency exceeded the digit $\mathrm{V}$ peak latency by $1 \mathrm{~ms}$ or more in $29(40 \%)$ of hands. Digit $V$ am-g plitude was greater than digit II amplitude in 27 $(39 \%)$ of hands.

Comparison of detection rafes of abnormality can be achieved by plotting the digital SAP peak latency against the corresponding palm to wrist conduction velocity (figs 3 and 4). Median conduction velocity in palm to wrist fibres was more than 2 standard deviations below the mean of the control group in $48(67 \%)$ of hands (fig 3 ). Ulnar conduction vel-

Table 2 Values in healthy control group $(N=53)$

\begin{tabular}{|c|c|c|}
\hline Measurement & Mean (range) & Standard Deviation \\
\hline $\begin{array}{l}\text { Digit II SAP } \\
\text { Amplitude }(\mu \mathrm{V}) \\
\text { Peak latency (ms) }\end{array}$ & $\begin{array}{r}21 \cdot 4(8-38) \\
2 \cdot 8(2 \cdot 5-3 \cdot 5)\end{array}$ & $\begin{array}{l}7 \cdot 2 \\
0 \cdot 25\end{array}$ \\
\hline $\begin{array}{l}\text { Digit V SAP } \\
\text { Amplitude }(\mu \mathrm{V}) \\
\text { Peak latency }(\mathrm{ms}) \\
\text { Median Palm-wrist SAP }\end{array}$ & $\begin{array}{r}16.0(9-28) \\
2.5(2 \cdot 1-3.3)\end{array}$ & $\begin{array}{l}6 \cdot 2 \\
0 \cdot 27\end{array}$ \\
\hline $\begin{array}{l}\text { Amplitude }(\mu \mathrm{V}) \\
\text { Peak latency }(\mathrm{ms}) \\
\text { Cond. Velocity (ms) } \\
\text { Ulnar Palm-wrist SAP }\end{array}$ & 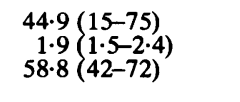 & $\begin{array}{c}14.7 \\
0.21 \\
6.7\end{array}$ \\
\hline $\begin{array}{l}\text { Amplitude }(\mu \mathrm{V}) \\
\text { Peak latency }(\mathrm{ms}) \\
\text { Cond. Velocity (ms) } \\
\text { Ratio Ulnar/Median palmar Conduction velocity } \\
\text { Difference Median-Ulnar Palmar SAP peak latency (ms) }\end{array}$ & $\begin{aligned} & 28.7(10-59) \\
& 1.91 \cdot 6-2 \cdot 6) \\
& 58 \cdot 4(47-71) \\
& 1 \cdot 0(0.83-1 \cdot 25) \\
&-0.03(-0.39-0.35)\end{aligned}$ & $\begin{array}{l}11 \cdot 0 \\
0 \cdot 20 \\
5 \cdot 8 \\
0 \cdot 12 \\
0 \cdot 16\end{array}$ \\
\hline
\end{tabular}




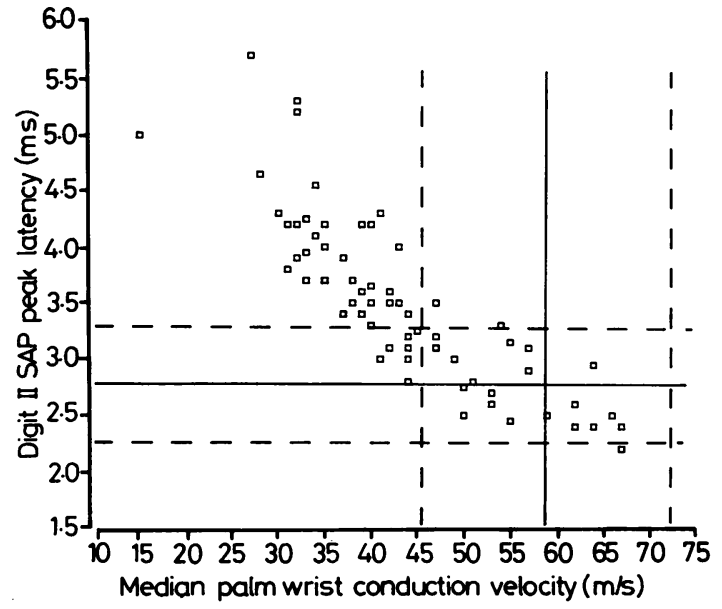

Fig 3 Comparison of digit II peak latency with median palm-wrist conduction velocity in 72 hands with possible carpal tunnel syndrome. Full lines indicate the mean value in the healthy control group, broken lines are at $2 S D$ from the mean.

ocity in the same segment was lower than the control values in eight hands (fig 4). Of these eight hands, six also had low median palmar conduction velocities and it was inferred that both nerves were affected either by low temperature or a more generalised neuropathy.

In order to assess whether a localised median nerve lesion co-existed in these hands, two further parameters were calculated: firstly, the difference in

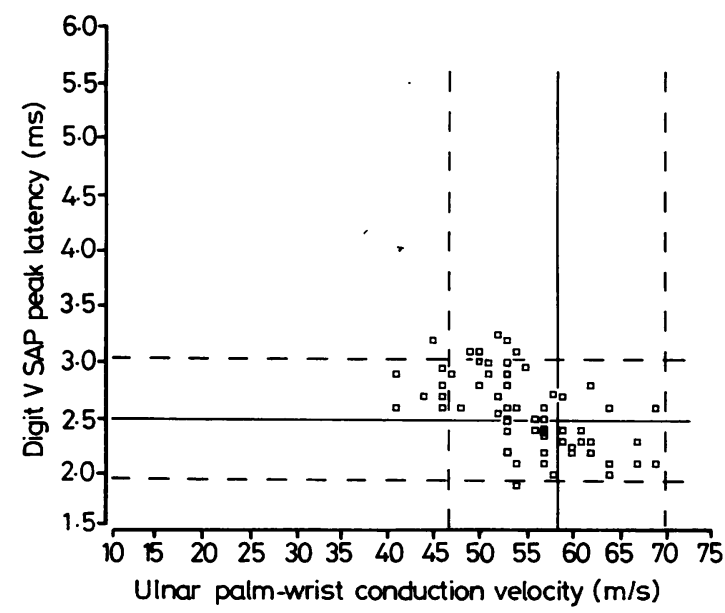

Fig 4 Comparison of digit $V$ peak latency with ulnar palm-wrist conduction velocity in 72 hands with possible carpal tunnel syndrome. Mean and $2 S D$ of the healthy control group are indicated as in fig 3. peak latency between ulnar and median palmar SAPs, and secondly, the ratio of ulnar to median conduction velocity in the palm segment. Values for these parameters in the control group are given in table 2. Of the six hands with low palmar velocity in both nerves, five had peak latency differences exceeding two standard deviations from the mean of the control group, implying a local median nerve lesion. The sixth patient had diabetes mellitus. Using the ratio parameter, three of the six patients had disproportionately low median palmar velocities. Of the two patients with low ulnar velocity but normal median velocity one had diabetes mellitus and the other rheumatoid arthritis.

\section{Patients with diseases unrelated to possible median nerve compression}

Median conduction velocity in the palm to wrist segment was $54.0 \mathrm{~m} / \mathrm{s}$ (SD 5.8 ); the corresponding values for the ulnar palm fibres was $54 \cdot 5$ (SD 5.3). These values are not significantly different from those of the normal controls ( $t$ test for independent samples: $p>0 \cdot 25$ ).

\section{Discussion}

The decision as to how to manage a patient with carpal tunnel syndrome is essentially based on the clinical findings; many investigators have pointed out the poor correlation between clinical features and electrophysiological findings. ${ }^{1718}$ Conservative measures such as night splints or local steroid injection are often unsuccessful in the long term and most authorities would favour early adequate surgical decompression. ${ }^{14}$ Although the results of the operation in terms of relief of pain are often good, recovery of motor and sensory function are proportional to the pre-operative deficit. If the operation is to be undertaken early, then a confident diagnosis must be made and in these early cases distal motor latency and even sensory action potential latency measurements may be normal. A sensitive technique to detect these cases would then be useful.

The palmar stimulation technique described here has proved more sensitive than digital SAPs and has been found to be robust, and easily applicable. It has been reported that palmar stimulation, whilst being more sensitive than digital stimulation, is not used routinely because it is painful. ${ }^{19}$ Many control subjects and patients in the present study were asked which was the more painful-digital or palmar stimulation; most could not distinguish between them and those who could said digital stimulation was the more painful.

If we propose to use a more sensitive technique, the question of false positive diagnoses must be born 

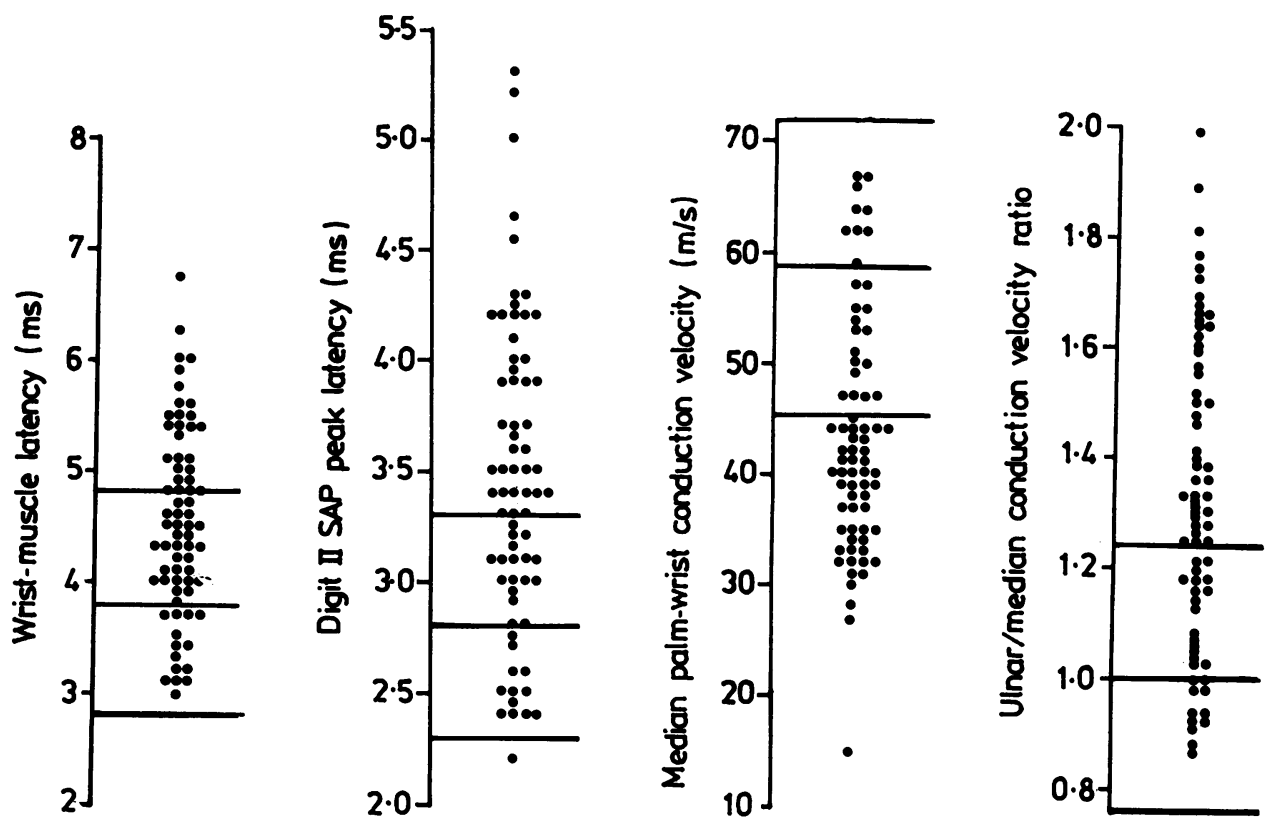

Fig 5 Comparison of wrist-muscle motor latency, peak latency of the digit II SAP, conduction velocity in median palm-wrist fibres and the ratio of ulnar to median conduction velocity in 72 hands with possible carpal tunnel syndrome. The percentages of hands falling beyond $2 S D$ from the mean of control hands were $33 \%, 53 \%, 67 \%$ and $60 \%$ respectively.

in mind. ${ }^{20}$ It is, of course, impossible to verify many of the diagnoses since even at operation, the nerve may appear normal. ${ }^{21}$ The response to operative treatment is also not totally reliable since there may well be a placebo effect. The only alternative is a careful follow-up of all operated and unoperated cases. The cases studied in this series were unselected except by the referral habits of clinicians. When the cases in which an abnormality on palmar stimulation was detected but other tests were within normal limits were studied, then no differences could be detected in the clinical history or physical findings.

Difficulties in interpretation of the measurements can arise when both median and ulnar palmar velocities are low and a decision as to whether the median fibres are disproportionately affected is required. Whilst peak latency difference of the palmar SAPs could be used, this measure is more affected by temporal dispersion of the potential, and the ratio of ulnar to median palmar conduction velocity, which uses onset latency in its calculation, is to be preferred.

In conclusion, SAPs recorded at the wrist in response to palmar stimulation of the median and ulnar nerves has been found to be a reliable technique for detecting abnormalities in the median nerve in patients suspected of having carpal tunne $B$ syndrome. In the author's view, it provides a usefur alternative to digital SAPs in the investigation of thiso condition.

I thank Dr RG Willison for his encouragement and helpful discussion. Financial support from Action Research for the Crippled Child is also gratefully acknowledged.

\section{References}

${ }^{1}$ Kimura J. Electrodiagnosis in Diseases of Nerve and Muscle. Principles and Practice. Philadelphia: FA Davis, 1983.

${ }^{2}$ Thomas JE, Lambert EH, Cseuz KA. Electrodiagnostic aspects of the carpal tunnel syndrome. Arch Neurol 1960;16:635-41.

${ }^{3}$ Buchthal F, Rosenfalk A. Sensory conduction from digit to palm and from palm to wrist in the carpal tunnel syndrome. J Neurol Neurosurg Psychiatry 1971; 34:243-52.

${ }^{4}$ Gilliatt RW, Sears TA. Sensory nerve action potentials in patients with peripheral nerve lesions. $J$ Neurol Neurosurg Psychiatry 1958;21:109-18.

${ }^{5}$ Mavor H, Shiozawa R. Antidromic digital and palmar nerve action potentials. Electroencephalogr Clin Neurophysiol 1971;30:210-21. 
${ }^{6}$ Buchthal F, Rosenfalk A, Trojaborg W. Electrophysiological findings in entrapment of the median nerve at wrist and elbow. $J$ Neurol Neurosurg Psychiatry 1974;37:340-60.

${ }^{7}$ Kimura J. A method for determining median nerve conduction velocity across the carpal tunnel. J Neurol Sci 1978;38:1-10.

${ }^{8}$ Kimura J. The carpal tunnel syndrome. Localisation of conduction abnormalities within the distal segment of the median nerve. Brain 1979; 102:619-35.

${ }^{9}$ Eklund G. A new electrodiagnostic procedure for measuring sensory nerve conduction across the carpal tunnel. Upsala J Med Sci 1975;80:63-4.

${ }^{10}$ Daube J. Percutaneous palmar nerve stimulation for carpal tunnel syndrome. Electroencephalogr Clin Neurophysiol 1977;43:139-40.

"Loong SC, Seah CS. Comparison of median and ulnar sensory nerve action potentials in the diagnosis of the carpal tunnel syndrome. J Neurol Neurosurg Psychiatry 1971;34:750-4.

${ }^{12}$ Cseuz KA, Thomas JE, Lambert EH, Love JG, Lipscomb PR. Long-term results of operation for carpal tunnel syndrome. Mayo Clinic Proc 1966;41:232-41.

${ }^{13}$ Phalen GS. The carpal-tunnel syndrome. Seventeen years' experience in diagnosis and treatment of six hundred fifty four hands. J Bone Joint Surg
1966;48A:211-28.

14 Phalen GS. Reflections on 21 years' experience with the carpal-tunnel syndrome. JAMA 1970;212:1365-7.

15 Dawson GD, Scott JW. The recording of nerve action potentials through the skin in man. $J$ Neurol Neurosurg Psychiatry 1949;12:259-67.

${ }^{16}$ Thomas PK. Motor nerve conduction in the carpal tunnel syndrome. Neurology (Minneap) 1960;10:104550.

${ }^{17}$ Goodwill CJ. The carpal tunnel syndrome. Long-term follow-up showing relation of latency measurements to response to treatment. Ann Phys Med 1965;8:1221.

${ }^{18}$ Shivde AJ, Dreizin I, Fisher MA. The carpal tunnel syndrome: a clinical-electrodiagnostic analysis. Electromyogr Clin Neurophysiol 1981;21:143-53.

${ }^{19}$ Gilliatt RW, Harrison MG. Nerve compression and entrapment. In: Asbury AK, Gilliatt RG eds. Peripheral Nerve Disorders. Butterwortnhs International Medical Reviews Neurology 4. London: Butterworths $1984 ; 243-86$.

${ }^{20}$ Gilliatt RW. Sensory conduction studies in the early recognition of nerve disorders. Muscle Nerve 1978; 1:352-9.

${ }^{21}$ Dawson DM, Hallett M, Millender LH. Entrapment Neuropathies. Boston: Little, Brown and Co. 1983. 